\title{
Antioxidative Activities of Natural Hydroxy-Bearing Cinnamaldehydes and Cinnamic Acids: A Comparative Study
}

\author{
Hong Jiang ${ }^{2}$, Sheng-Ling Sun ${ }^{3}$, Chao Zhang ${ }^{2}$, Erdong Yuan ${ }^{1}$, Qing-Yi Wei ${ }^{{ }^{*}}$, \\ Zhen Zeng ${ }^{2}$ \\ ${ }^{1}$ College of Light Industry and Food Science, South China University of Technology, Guangzhou 510640, ${ }^{2}$ Department of \\ Chemistry, College of Science, Huazhong Agricultural University, Wuhan 430070, \\ ${ }^{3}$ State Key Laboratory of Isotope Geochemistry, Guangzhou Institute of Geochemistry, Chinese Academy of Sciences, Guangz \\ hou 510640, China.
}

*For correspondence: Email: feweiqingyi@scut.edu.cn; Tel: +86-020-87112594; Fax: +86-020-87112594

Received: 2 November 2013

Revised accepted: 9 October 2013

\begin{abstract}
Purpose: To determine the potent antioxidants among six hydroxy-bearing cinnamaldehyde compounds and their corresponding acids.

Methods: The antioxidative activities were evaluated by scavenging 2, 2'-diphenyl-1-picrylhydrazyl (DPPH) free radicals and anti-hemolysis of human red blood cells (RBCs). Fourier transform infrared spectrometry (FT-IR, nuclear magnetic resonance (NMR) and mass spectrometer(MS) evaluations were used to determine the synthesized compounds.

Results: The scavenging ability of the compounds on DPPH radicals was in the following rank order: caffeic aldehyde $(\boldsymbol{F}) \approx$ caffeic acid $(\boldsymbol{C})>$ vitamin $C(\boldsymbol{V C})>0$-coumaraldehyde $(\boldsymbol{D})>p$-coumaric acid $(\boldsymbol{B})>$ p-coumaraldehyde $(\boldsymbol{E}) \approx 0$-coumaric acid. Inhibitory ability against 2'-Azobis(2-methylpropionamidine) dihydrochloride $(A A P H)$-induced erythrocyte hemolysis was ranked as follows: o-coumaraldehyde $(D)>$ p-coumaraldehyde $(\boldsymbol{E}) \approx$ caffeic aldehyde $(\boldsymbol{F})>$ caffeic acid $(\boldsymbol{C}) \approx 0$-coumaric acid $(\boldsymbol{A})>p$-coumaric acid (B) > Vitamin C. The corresponding inhibition time ( $\left.t_{\text {inh }}\right)$ of $D$ and $V c$ was 63.6 , and $23.7 \mathrm{~min}$, respectively.

Conclusion: Cinnamaldehydes demonstrated superior antioxidative activities to their corresponding acids. DPPH scavenging ability correlated directly with the number of hydroxyl groups on the catechol ring while the degree of lipophilicity of the compounds may be proportional to their anti-hemolytic activity.
\end{abstract}

Keywords: DPPH scavenging, Cinnamaldehyde, Cinnamic acid, Antioxidative, Hemolysis.

Tropical Journal of Pharmaceutical Research is indexed by Science Citation Index (SciSearch), Scopus, International Pharmaceutical Abstract, Chemical Abstracts, Embase, Index Copernicus, EBSCO, African Index Medicus, JournalSeek, Journal Citation Reports/Science Edition, Directory of Open Access Journals (DOAJ), African Journal Online, Bioline International, Open-J-Gate and Pharmacy Abstracts

\section{INTRODUCTION}

Free-radical-initiated peroxidation of membrane lipid is associated with a variety of chronic health problems, such as cancer, hypertension, atherosclerosis, diabetes, inflammation, ischemia, Alzheimer, Parkinsonism and aging
[1]. Natural antioxidants are capable of trapping radicals to protect the membrane lipids from free radical chain reactions. Therefore, inhibition of free radical-induced oxidative damage by supplementation of antioxidants has become an attractive and promising therapeutic strategy for reducing the risk of these diseases $[1,2]$. 
Hydroxy-bearing cinnamic acids are naturally abundant antioxidants in our diet, such as $p$ coumaric acid, and caffeic acid, which have a variety of biological activities, such as anticancer [3], antimutation [4], and antioxidation [5], hepatoprotective etc $[6,7]$. Some hydroxybearing cinnamaldehydes, such as ocoumaraldehyde from bark of cinnamon, $p$ coumaraldehyde, ferulaldehyde, and caffeic aldehyde have been widely studied and found to be good bioactive compounds. Much attention has been paid to their antioxidative activities [814]. But the comparative studies on the antioxidative effects of the hydroxy-bearing cinnamaldehydes with their corresponding acids are few. The objective of this study, therefore, is to compare the antioxidative activities of hydroxy-bearing cinnamaldehydes with their corresponding acids (Figure 1).

The antioxidative activities were evaluated by both their scavenging of 2, 2'-diphenyl-1picrylhydrazyl (DPPH) free radicals and their anti-hemolysis of human red blood cells (RBCs). DPPH method is often regarded as a rapid, simple, sensitive and practical assay for the evaluation of radical scavenging capacity of antioxidants [2]. Human red blood cell hemolysis test provides a good approach for evaluating at antioxidative activities at cell membrane level [2].<smiles>O=CC=Cc1ccccc1O</smiles>

Figure 1: Structure of test compounds A: o-coumaric acid; B: p-coumaric acid; C: caffeic acid; D: ocoumaraldehyde; E: p-coumaraldehyde; $\mathrm{F}$ : caffeic aldehyde;

\section{EXPERIMENTAL}

\section{Materials}

O-Coumaric acid; $p$-Coumaric acid; Caffeic acid 2, 2'-Diphenyl-1-picrylhydrazyl (DPPH) and 2, 2'azo-bis (2-amidinopropane) dihydrochloride (AAPH) were obtained from Sigma. OCoumaraldehyde; $p$-Coumaraldehyde; Caffeic aldehyde were Synthesized in our lab. Other chemicals were purchased from Sinopharm Chemical Reagent Co. Ltd. All chemicals and solvents were of analytical grade. Distilled water was used throughout the entire experiment.

\section{Apparatus}

Synthesized compounds were purified on a silica gel H (32-63 mesh) column and identified by IR, ${ }^{1} \mathrm{H}$ NMR, and MS analysis. IR spectra were recorded on Fourier-transform Model-Nexus 870 infrared spectrometer (Thermo Nicolet Corp.) and samples prepared as $\mathrm{KBr}$ disks, and only the most significant absorption bands were reported ( $v$ max, $\left.\mathrm{cm}^{-1}\right) .{ }^{1} \mathrm{H}$ NMR data were acquired at room temperature on a Bruker AV 600-MHz (Bruker Corp), $\mathrm{CDCl}_{3}$ or DMSO-d6 was used as solvent; Mass spectrometry was performed on a Saturn 2000 mass spectrometer (Varian Inc.) while Spectronic Genesys 10 Bio UV/VIS spectrophotometer (Thermo Electron Corp.) was used for DPPH and RBC hemolysis assays.

\section{Preparation of hydroxycinnamaldehyde}

Cinnamaldehydes are usually synthesized by cross aldol condensation between substituted benzaldehydes and acetaldehyde. However, when strong electron-donating groups, such as hydroxyl or methoxyl groups, are present on the phenyl ring, the corresponding cinnamaldehydes can't be prepared by this procedure. To prepare hydroxyl-bearing cinnamaldehydes, reduction of the corresponding cinnamoyl chloride is a good alternative method [15]. In this work cinnamoyl chlorides were readily reduced to the corresponding aldehydes in good yields with no further reduction to the corresponding alcohols. However, before reduction, the hydroxyl group on the benzene ring should be protected by acetylation, otherwise the yields of the target products were very low (Scheme 1). The synthetic route is outlined as follows according to literature with some modifications [15]. The synthesis of compounds $\mathbf{D}-\mathbf{F}$ is exemplified by the synthesis of $p$-hydroxylcinnamaldehyde (compound E). Generally, acetic anhydride (2 $\mathrm{mL}, 0.021 \mathrm{~mol}$ ) was added dropwise to the stirred mixture of compound 1 (2.28 g, 0.014 mol) and sodium hydroxide $(1.48 \mathrm{~g}, 0.37 \mathrm{~mol})$ in water $(18 \mathrm{~mL})$ at $10{ }^{\circ} \mathrm{C}$. The mixture was agitated at $10{ }^{\circ} \mathrm{C}$ for $2 \mathrm{hr}$, at room temperature for $1 \mathrm{~h}$, and then was acidified with $\mathrm{HCl}$ to $\mathrm{pH}<3$. After filtration, the white solid product 2 was collected and dried in vacuum. Compound 2 (1.6 g, 0.0078 $\mathrm{mol})$ was added to thionyl chloride $(4.3 \mathrm{~mL}, 0.06$ mol) with stirring. After reaction at $75{ }^{\circ} \mathrm{C}$ for $3 \mathrm{~h}$, the intermediate 3 was obtained by removing the residual solvent by rotary evaporation. Triphenyl phosphine $(2.62 \mathrm{~g}, 0.01 \mathrm{~mol})$ was added to the solution of intermediate $3(2.25 \mathrm{~g}, 0.01 \mathrm{~mol})$ in 
acetone $(10 \mathrm{~mL})$ with stirring within $5 \mathrm{~min}$, and then $\left[\mathrm{Cu}\left(\mathrm{PPh}_{3}\right)_{2}\right] \mathrm{BH}_{4}(4.62 \mathrm{~g}, 0.008 \mathrm{~mol})$ was added. After reaction at room temperature for 1 $\mathrm{h}$, solid compound $\mathbf{4}$ was collected by filtration. Compounds 4 (1.9 g, $0.01 \mathrm{~mol})$ was hydrolyzed at $45{ }^{0} \mathrm{C}$ for $2 \mathrm{~h}$ in sodium hydroxide solution $(10 \%, 15 \mathrm{~mL})$, then the solution was acidified to $\mathrm{pH}<2$ with $\mathrm{HCl}$, extracted with $\mathrm{CH}_{2} \mathrm{Cl}_{2}$, dried over $\mathrm{MgSO}_{4}$. After removal of the solvent under reduced pressure the residual paste was purified by column chromatography (ethyl acetate/petroleum ether $=2: 1)$, the pure target compound $\mathbf{5}$ (compound $\mathbf{E}$ ) was obtained. Other compounds were synthesized in similar way.

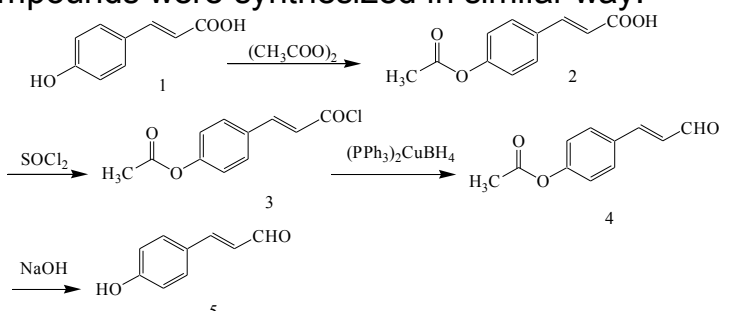

Scheme 1: The synthetic route for compound E

\section{Determination of DPPH radical scavenging activity}

The antiradical activity of compounds was determined spectrophotometrically by monitoring the disappearance of DPPH according to a reported procedure with some modifications [2]. Each sample at different concentration in ethanol $(2 \mathrm{~mL})$ was mixed with $2 \mathrm{~mL}$ of ethanolic solution containing $0.15 \mathrm{mM} \mathrm{DPPH}$. The mixture was shaken vigorously, and then left to stand for 30 min in the dark. The absorbance was measured at $517 \mathrm{~nm}$. The absorbance of the control was obtained by replacing the sample with ethanol. DPPH radical scavenging activity (D) of the sample was calculated as in Eq 1.

$$
D(\%)=\left[\left(A_{c}-A_{t}\right) / A_{c}\right] \times 100
$$

Where $A_{c}$ is the absorbance of control (i.e., without test sample) and $A_{t}$ the absorbance of the test sample. Vitamin $C$ was used as a reference compound.

\section{Preparation of Red Blood Cells( RBCs)}

Human erythrocytes collected from healthy volunteer donors were provided by Red Cross Center for Blood, Wuhan, China. After washing three times with phosphate-buffered saline (PBS: $150 \mathrm{mM} \mathrm{NaCl}, 8.1 \mathrm{mM} \mathrm{Na} \mathrm{HPO}_{4}, 1.9 \mathrm{mM}$ $\mathrm{NaH}_{2} \mathrm{PO}_{4}$, and $50 \mu \mathrm{M}$ EDTA, $\mathrm{pH}$ 7.4) to remove the residual plasma, the erythrocytes were centrifuged at $2000 \mathrm{rpm}$ for exactly $10 \mathrm{~min}$ to obtain compact erythrocytes for experimental use.

\section{Assay for hemolysis}

The $5 \%(w / v)$ suspension of RBCs in PBS $(\mathrm{pH}$ 7.4) was incubated under air atmosphere at 37 ${ }^{0} \mathrm{C}$ for $5 \mathrm{~min}$, and hemolysis was initiated by introducing a PBS solution of AAPH [16]. This reaction mixture was incubated at $37^{\circ} \mathrm{C}$ with gentle shaking. The extent of hemolysis was determined spectrophotometrically by measuring the absorbance of hemolysate at $540 \mathrm{~nm}$. Briefly, aliquots of the reaction mixture were taken at appropriate time intervals, diluted with $0.15 \mathrm{M}$ $\mathrm{NaCl}$, and centrifuged at $2000 \mathrm{rpm}$ for $10 \mathrm{~min}$ to separate the RBCs. The percentage hemolysis was determined by measuring the absorbance (A) of the supernatant at $540 \mathrm{~nm}$ and compared with that $(B)$ of complete hemolysis by treating the same RBCs suspension with distilled water. The percentage hemolysis was calculated from ratio of $(A / B) \times 100$. In the case of antihemolysis experiments, the tested compounds dissolved in dimethyl sulfoxide (DMSO) to a final concentration of $30 \mu \mathrm{M}$ were added and incubated before the addition of $50 \mathrm{mM} \mathrm{AAPH}$. The final concentration of DMSO was $0.1 \%(\mathrm{v} / \mathrm{v})$ and did not interfere with the determination.

\section{Statistical analysis}

The data obtained in this study were expressed as mean \pm standard deviation (SD). Statistical comparisons were made using Student's -ttest. $P$ $<0.05$ was considered to be significant. Data were analysed using SPSS statistic program (version 13.0, SPSS Inc, Chicago, IL, USA).

\section{RESULTS}

\section{Structural characteristics}

Compound D: ${ }^{1} \mathrm{H}$ NMR $\left(\mathrm{CDCl}_{3}, \delta(\mathrm{ppm})\right): 9.69(\mathrm{~d}$, $1 \mathrm{H}, J=7.8 \mathrm{~Hz}, \mathrm{CHO}), 7.81$ (d, 2H, J=16.2 Hz, $\mathrm{HC}=\mathrm{C}, \mathrm{ArH}), 7.52(\mathrm{~d}, 1 \mathrm{H}, \mathrm{J}=7.8 \mathrm{~Hz}, \mathrm{ArH}), 7.31$ (d, 1H, J=8.4 Hz, ArH), 6.99 (d, 1H, J=7.2 Hz, ArH), 6.90(dd, $1 \mathrm{H}, J=16.2,7.8 \mathrm{~Hz}, \mathrm{C}=\mathrm{CH}), 6.68$ (s, 1H, OH). IR (KBr, cm $\left.{ }^{-1}\right)$ v: 3180(-OH), 1660 ($\mathrm{CHO}$ ), 1594, 1464, 1401 (benzene ring). MS, $\mathrm{m} / \mathrm{z}$ (\%): $149\left((\mathrm{M}+1)^{+}(100.0)\right), 131(66), 97$ (19), 57 (20).

Compound E: ${ }^{1} \mathrm{H}$ NMR $\left(\mathrm{CDCl}_{3}, \delta(\mathrm{ppm})\right)$ : $9.66(\mathrm{~d}$, $1 \mathrm{H}, \mathrm{J}=7.8 \mathrm{~Hz}, \mathrm{CHO}), 7.49(\mathrm{~d}, 2 \mathrm{H}, \mathrm{J}=8.4 \mathrm{~Hz}, \mathrm{ArH})$, $7.43(\mathrm{~d}, 1 \mathrm{H}, \mathrm{J}=15.6 \mathrm{~Hz}, \mathrm{HC}=\mathrm{C}), 6.91(\mathrm{~d}, 2 \mathrm{H}$, $J=8.4 \mathrm{~Hz}$, ArH), $6.64(\mathrm{dd}, 1 \mathrm{H}, J=15.6,7.8 \mathrm{~Hz}$, $\mathrm{C}=\mathrm{CH}), 5.80(\mathrm{~s}, 1 \mathrm{H},-\mathrm{OH}) . \mathrm{IR}\left(\mathrm{KBr}, \mathrm{cm}^{-1}\right) \mathrm{v}: 3433$ (-OH), 1641 (-CHO), 1600, 1577, 1508, 1507 (benzene ring). MS, $m / z(\%): 149\left((M+1)^{+} 100.0\right)$, 131 (27), 91 (31). 
Compound F. ${ }^{1} \mathrm{H}$ NMR $\left(\left(\mathrm{CD}_{3}\right)_{2} \mathrm{SO}, \delta\right.$ (ppm)): 9.80 (S, $1 \mathrm{H}, \mathrm{OH}), 9.57(\mathrm{~d}, 1 \mathrm{H}, J=7.8 \mathrm{~Hz}, \mathrm{CHO}), 9.28$ (S, $1 \mathrm{H}, \mathrm{OH}), 7.57(\mathrm{~d}, 1 \mathrm{H}, J=16.2 \mathrm{~Hz}, \mathrm{HC}=\mathrm{C})$, $7.10(\mathrm{~m}, 2 \mathrm{H}, \mathrm{ArH}), 6.82(\mathrm{~d}, 1 \mathrm{H}, J=7.8 \mathrm{~Hz}, \mathrm{ArH})$, $6.56(\mathrm{dd}, 1 \mathrm{H}, J=16.2,7.8 \mathrm{~Hz}, \mathrm{C}=\mathrm{CH})$. IR $(\mathrm{KBr}$, $\left.\mathrm{cm}^{-1}\right)$ v: $3427(-\mathrm{OH}), 1660(-\mathrm{CHO}), 1597,1445$, (benzene ring). MS, $m / z\left((\%): 164\left((\mathrm{M})^{+} 84\right), 147\right.$ (64.6), 83 (100).

\section{DPPH free radical scavenging activity}

Using vitamin $\mathrm{C}(\mathbf{V c})$ as a reference compound, the results of DPPH free radical scavenging activities of cinnamaldehydes and cinnamic acids were showed in Figure 2. All the tested compounds could quench DPPH radicals, and the scavenging ability of them increased within the test concentrations, for compound $\mathbf{C}, \mathbf{F}$ and Vc in the range of 0-150 $\mu \mathrm{M}$, while for compound A, B, D and $\mathbf{E}$ in the range of $100-500 \mu \mathrm{M}$. The rank order of scavenging activity on DPPH radicals was: caffeic aldehyde $(\mathbf{F}) \approx$ caffeic acid (C) $>$ Vc $>$ o-coumaraldehyde (D) $>p$-coumaric acid $($ B) $>p$-coumaraldehyde $($ E) $\approx 0$-coumaric acid (A). The result of DPPH scavenging ability revealed that caffeic aldehyde (compound $\mathbf{F}$ ) and caffeic acid (compound $\mathbf{C}$ ) with the o-dihydroxyl groups on the catechol ring were the most effective one, and then followed by coumaraldehydes and coumaric acids (with only one hydroxyl group) .

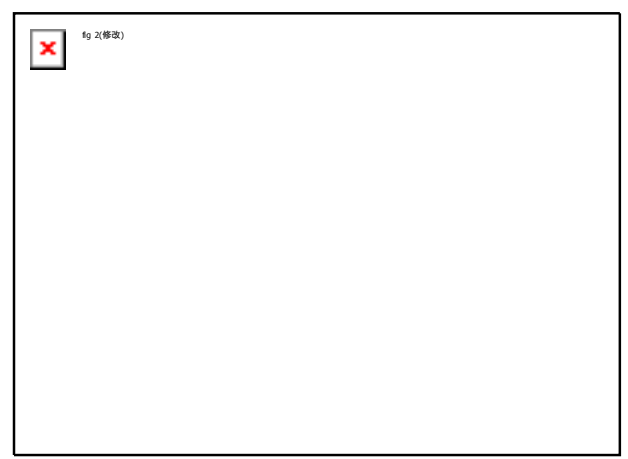

Figure 2 DPPH free radical scavenging activities of tested compounds $(O=F, \nabla=C, \nabla=V C, i=D, \boldsymbol{\square}=$ $\mathrm{B}, \mathrm{X}=\mathrm{A}$ )

\section{Inhibitory activity against AAPH-induced erythrocyte hemolysis}

Erythrocytes were continuously destroyed via AAPH oxidation in a time-dependent manner; however, hemolysis was still lagged in the absence of extraneous antioxidants because the endogenous antioxidants, e.g., vitamin $E$ and/or ubiquinol-10, in the membrane which can postpone erythrocytes from hemolysis. The lag time of hemolysis, $t_{\text {lag }}$, refers to the turning point from the inhibition period of hemolysis to the restoration period of hemolysis curve, which can be used to value the activity of an antioxidant. The lag time was $114.6 \mathrm{~min}$ when the concentration of AAPH was $50 \mathrm{mM}$ (see control in Figure 3). In order to eliminate the influence of erythrocytes from different donors, inhibition time $\left(t_{\text {inh }}=t_{\text {lag }}-t_{\text {lag } 0}, t_{\text {lago }}=114.6\right.$ is the lag time in the absence of added antioxidants) has been designated to compare their antioxidative activities in RBCs system. The inhibition activities produced by Hydroxy-bearing cinnamaldehydes and cinnamic acids are shown in Figure 3. Addition of hydroxy-bearing cinnamaldehydes or cinnamic acids (ArOHs) to the $5 \%$ RBC suspension significantly increased the inhibition time of the RBCs. When initiated with $50 \mathrm{mM}$ of AAPH, the lag times produced by $30 \mu \mathrm{M}$ compounds D, E , C , F , A , B , VC were 178.2, 163.1, 162.2, 160.2, 158.2, 152.5, and $138.3 \mathrm{~min}$, respectively. The corresponding inhibition times, $\mathrm{t}_{\text {inh }}$, were $63.6,48.5,47.6,45.6$, 43.6, 31.9, and $23.7 \mathrm{~min}$, respectively. Therefore, the inhibitory ability against AAPHinduced erythrocyte hemolysis is as the following sequence: o-coumaraldehyde (D) $>p$ coumaraldehyde $(E) \approx$ caffeic aldehyde $(F)>$ caffeic acid (C) $\approx 0$-coumaric acid (A) $>p$ coumaric acid (B) > Vitamin C.

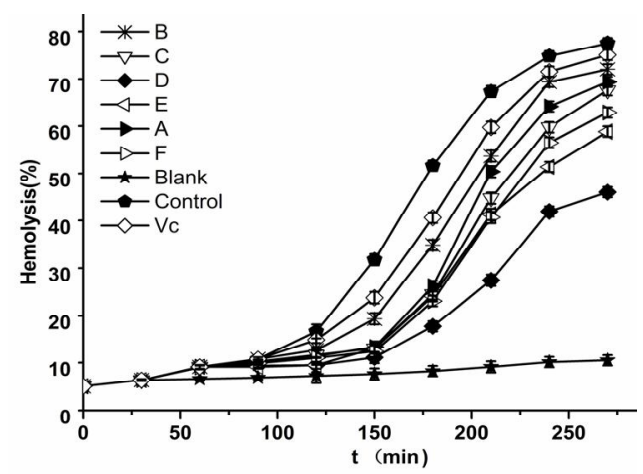

Figure 3: Inhibition of human erythrocyte hemolysis by antioxidants. The human erythrocytes (5\%) hemolysis was induced by $50 \mathrm{mM}$ AAPH in PBS $(\mathrm{pH}$ 7.4) at $37{ }^{\circ} \mathrm{C}$ in presence of various compound from $\mathbf{A}$ to $\mathbf{F}$ and $\mathbf{V c}(30 \mu \mathrm{M})$. Blank = human erythrocytes (5 $\%)$ with no AAPH and ntest compounds. Control = human erythrocytes (5\%) without test compounds but contains $50 \mathrm{mM} \mathrm{AAPH}$

\section{Influence of the concentration on the inhibitory activities of compound D}

Compound o-coumaraldehyde (D) was the most active compound in anti-hemolysis of RBCs among them, so the influence of the concentrations on the inhibition activities of compound $\mathbf{D}$ was further investigated (Figure 4). It is evident that compound $\mathbf{D}$ protected the erythrocyte membrane from hemolysis in a 
concentration-dependent manner. The higher the concentration of compound D was added, the less the hemolysis of RBCs was produced.

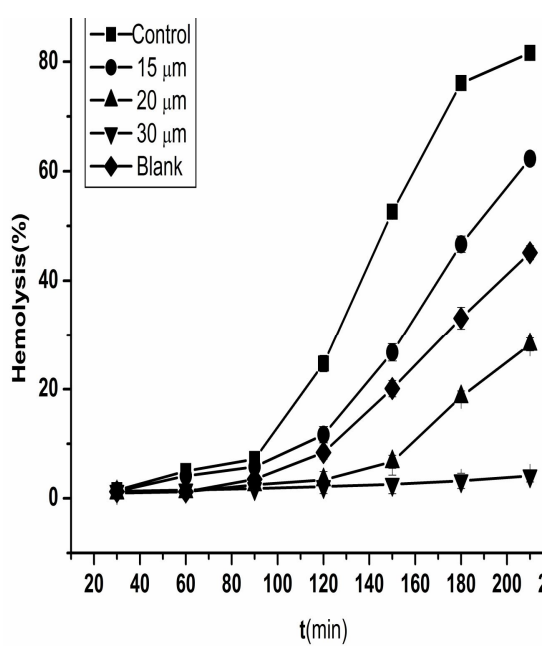

Figure 4: Relationship between concentration of ocoumaraldehyde (E) and hemolysis of human erythrocyte. Hemolysis of human erythrocytes (5\%) induced by $50 \mathrm{mM}$ AAPH in PBS $\left(\mathrm{pH} \mathrm{7.4)}\right.$ ) at $37{ }^{\circ} \mathrm{C}$ in presence of various concentrations of compound $\mathbf{E}$.

The compounds D (o-coumaraldehyde) displayed the strongest anti-hemolysis activities among all the tested compounds, while Vitamin $\mathrm{C}$ demonstrated the least activity. Vitamin $\mathrm{C}$ is a water-soluble compound, so it is hard for it to adhere to the polyunsaturated fatty acids in the membrane of RBCs. It is found that cinnamaldehydes are more effective to inhibit the hemolysis than their corresponding acids which can also be explained by the same reason that the acid group is more hydrophilic group than aldehyde group. Cinnamaldehydes are more fatsoluble than their corresponding acids, so it is easier for cinnamaldehydes to adhere to the lipid part of erythrocytes than their corresponding acids, and thus cinnamaldehydes showed stronger hemolysis inhibitory activities than their corresponding acids. Certain phenolic compounds may incorporate into the hydrophobic core of the membrane bilayer, causing a reduction in membrane fluidity [1719]), which in turn may limit diffusion of free radicals and improve the antioxidative effectiveness. Thus, direct interactions of phenolic compounds with cell membrane may alter membrane stabilization and their antioxidative activities. It is obvious that compounds with only one hydroxyl group (coumaraldehydes) were much more effective in RBCs hemolysis test than in DPPH system. Interestingly, o-coumaraldehyde possessed the strongest inhibitory activities among them in RBCs hemolysis test. The strong antioxidative activities of $\mathrm{O}$-coumaraldehyde in RBCs hemolysis test provide useful evidence to explain its various biological functionalities $[9,11,12,14]$, such as antimicrobial, anti-inflammatory, and as a good candidate for cancer therapy. Another possible cause for the higher activities of aldehydes is that the carbonyl group of cinnamaldehydes can easily combine with the residual amino group of the protein of RBCs forming reversible imine structure [20]. This will lead to the closer contact of cinnamaldehydes with the membrane and hence makes the free radicals attack on the membrane hindered, which in turn makes the antioxidative effectiveness of cinnamaldehydes improved. Their corresponding acids can't form imine structure with protein, so they had much less effect on the RBCs membrane and therefore demonstrated much less antioxidative activities.

\section{CONCLUSION}

In both systems cinnamaldehydes had significantly higher activities than their corresponding acids. Furthermore, cinnamaldehydes demonstrated much better activities in anti-hemolysis of RBCs than in scavenging DPPH radicals, especially for coumaraldehydes. This makes the cinnamaldehydes more desirable as antioxidant functional food additives than their corresponding acids. However the potential application of cinnamaldehydes in various foods and regulatory acceptance needs further investigation.

\section{ACKNOWLEDGEMENT}

This work was supported by the Fundamental Research Funds for the Central Universities, SCUT (2012ZM0070) and HZAU (2011PY088) and the National Natural Science Foundation of China (21002034) and the National Key Technology R\&D Program of China in the 12th five-year period (2012BAD33B11)

\section{REFERENCES}

1. Vendemiale G, Grattagliano I, Altomare E. An update on the role of free radicals and antioxidant defense in human disease. Int J Clin Lab Res 1999; 29: 4955.

2. Wei QY, Jiang $H$, Zhang JX, Guo PF, Wang $H$. Synthesis of N-hydroxycinnamoyl amino acid ester analogues and their free radical scavenging and antioxidative activities. Med Chem Res 2012; 21: 1905-1911.

3. Boudreau LH, Picot N, Doiron J, Villebonnet $B$, Surette ME, Robichaud G.A, Touaibia M. Caffeoyl and cinnamoyl clusters with anti-inflammatory and anticancer effects-Synthesis and structure-activity relationship. New J Chem 2009; 33: 1932-1940.

4. Yamada J, Tomita Y. Antimutagenic activity of caffeic acid and related compounds. Biosci Biotech Biochem 1996; 60: 328-329. 
5. Wu WM, Lu L, Long Y, Wang $T$, Liu L, Chen $Q$, Wang $R$. Free radical scavenging and antioxidative activities of caffeic acid phenethyl ester (CAPE) and its related compounds in solution and membranes: A structure-activity insight. Food Chem 2007; 105: 107-115.

6. Perez-Alvarez V, Bobadilla RA, Muriel P. Structurehepatoprotective activity relationship of $3,4-$ dihydroxycinnamic acid (caffeic acid) derivatives. J Appl Toxicol 2001; 21: 527-531.

7. Narasimhan $B$, Belsare $D$, Pharande $D$, Mourya $V$, Dhake A. Esters, amides and substituted derivatives of cinnamic acid: synthesis, antimicrobial activity and QSAR investigations. Eur J Med Chem 2004; 39: 827-834.

8. Choi J, Lee KT, Ka H, Jung WT, Jung HJ, Park HJ. Constituents of the essential oil of the Cinnamomum cassia stem bark and the biological properties. Arch Pharm Res 2001; 24: 418-423.

9. Andreeva IM, Babeshko OM, Bondarenko EM, Barchan IA, Lyashik OT. Structure and antimicrobial activity of 2-hydroxycinnamic aldehyde derivatives. Khimiko-Farmatsevticheskii Zhurnal 1985; 19: 177179.

10. Khatib A, Kim MY, Chung SK. Anti-inflammatory activities of cinanamomum burmanni. Food $\mathrm{Sci}$ Biotech 2005; 14: 223-227.

11. Gan FF, Chua YS, Scarmagnani S, Palaniappan $P$ Franks $M$, Poobalasingam $T$, Bradshaw TD, Westwell $A D$, Hagen T. Structure-activity analysis of 2 '-modified cinnamaldehyde analogues as potential anticancer agents. Biochem Bioph Res Co 2009; 387: 741-747.

12. Hong SH, Kim J, Kim JM, Lee SY, Shin DS, Son KH, Han DC, Sung YK, Kwon BM. Apoptosis induction of 2-hydroxycinnamaldehyde as a proteasome inhibitor is associated with ER stress and mitochondrial perturbation in cancer cells. Biochem Pharm 2007; 74: 57-565.

13. Phitak $T$, Choocheep $K$, Pothacharoen P, Pompimon $W$ Premanode $B$, Kongtawelert $P$. The effects of $p$ hydroxycinnamaldehyde from Alpinia galanga extracts on human chondrocytes. Phytochemistry 2009; 70: 237-243.

14. Cioffi G, D'Auria M, Braca A, Mendez J, Castillo A Morelli I, De Simone F, De Tommasi N. Antioxidant and free-radical scavenging activity of constituents of the leaves of Tachigalia paniculata. $J$ Nat Prod 2002, 65: 1526-1529.

15. Tachibana $S$, Ito $K$, Sumimoto $M$. A convenient synthesis of p-hydroxy- and $p$ methoxycinnamaldehydes. Mokuzai Gakkaishi 1989; 35: 1154-1158.

16. Niki E. Free radical initiators as source of water or lipidsoluble peroxyl radicals. Methods in Enzymology 1990; 186: 100-108.

17. Arora A, Byrem TM, Nair MG, Strasburg GM. Modulation of liposomal membrane fluidity by flavonoids and isoflavonoids. Arch Biochem Bioph 2000; 373: 102-109.

18. Chen YF, Deuster P. Comparison of quercetin and dihydroquercetin: Antioxidant-independent actions on erythrocyte and platelet membrane. Chem-Biol Interact 2009; 182: 7-12.

19. Youdim KA, Martin A, Joseph JA. Incorporation of the elderberry anthocyanins by endothelial cells increases protection against oxidative stress kuresh A. Free Radical Bio Med 2000; 29: 51-60.

20. Wei QY, Xiong JJ, Jiang $H$, Zhang C, Ye W. The antimicrobial activities of the cinnamaldehyde adducts with amino acids. Int J Food Microbiol 2011; 150: 164-170. 